\title{
Análise da Configuração Textual: uma aula de L. S. Vigotski
}

\author{
Amabriane da Silva Oliveira Shimite \\ Fabiana Oliveira Koga'
}

'Universidade Estadual Paulista (UNESP), Marília/SP - Brasil

RESUMO - Análise da Configuração Textual: uma aula de L. S. Vigotski. Pela análise do texto/aula O pensamento do escolar objetivou-se refletir sobre a síntese dos conceitos que constituem a Teoria Histórico-Cultural, com destaque para o desenvolvimento da consciência humana. O método para tal ação foi a análise documental e o procedimento de interpretação empregado foi a análise da configuração textual. Foram analisados aspectos do contexto histórico e da tradução, bem como a síntese de conceitos apresentada por Vigotski para professores em formação. A tentativa de esclarecer, exemplificar, contextualizar e demonstrar aos professores a necessidade de refletir sobre os conceitos da Teoria Histórico-Cultural na prática pedagógica explorou o pensamento conceitual no processo de desenvolvimento da criança.

Palavras-chave: Teoria Histórico-Cultural. Consciência. Generalização. Humanização.

ABSTRACT-Textual Configuration Analysis: a lesson by L. S. Vigotski. The
analysis of the text/class The student's thinking was carried out a reflect-
ing on the synthesis of the concepts that constitute the Historical-Cultural
Theory, with emphasis on the development of human consciousness. The
method for such action was the documentary analysis and the interpreta-
tion procedure employed was the textual configuration analysis. Aspects of
the historical context and translation were analyzed, as well as the synthe-
sis of concepts presented by Vigotski for teachers in training. The attempt
to clarify, exemplify, contextualize and demonstrate to teachers the need
to reflect on the concepts of the Historical-Cultural Theory, in pedagogical
practice, explored the conceptual thinking in the process of child develop-
ment. Keywords: Historical-Cultural Theory. Consciousness. Generalization. Humanization.

Educação \& Realidade, Porto Alegre, v. 45, n. 3, e97992, 2020. 
Análise da Configuração Textual

\section{Introdução}

Os estudos relacionados ao desenvolvimento humano e à área da Educação, abordados por Arroyo (2014; 2007), Saviani (2013), Freire (2007; 2018), Duarte (1996; 2013), dentre tantos importantes pesquisadores brasileiros, apresentam um contexto reflexivo a respeito da realidade vivenciada e enfrentada no ambiente escolar. Tal ação conduz a busca pela emancipação da pessoa humana por meio da educação e, principalmente, pelo reconhecimento das diferenças humanas, desafiando o professor à contínua avaliação do seu trabalho pedagógico (Dainez, 2017; Dainez; Smolka, 2014; Skliar, 2006; Omote, 2004; Goffman, 1963). De acordo com Mello (2010, p. 728), “[...] a maior dificuldade dos professores e professoras [...] é dominar o significado dos conceitos utilizados pelos autores e o modo como os articulam a partir da lógica de análise que utilizam". A reflexão das autoras desse artigo sobre o seu trabalho pedagógico conduziu ao aprofundamento dos estudos sobre a Educação Especial no ambiente escolar e das pesquisas científicas realizadas no âmbito da pós-graduação em Educação, aos textos de autoria de Lev Semyonovich Vigotski.

A obra de Vigotski apresenta o árduo trabalho intelectual do teórico quanto à ênfase a conceitos como: pensamento, consciência, generalização, mediação, compensação e linguagem como imprescindíveis para o desenvolvimento humano, na busca pela humanização. Nesse cenário, Dainez (2017) aponta a Teoria Histórico-Cultural como agente reflexivo-fundamentador frente às dificuldades encontradas no contexto da Educação no Brasil e, por isso, a necessidade de aprofundar os estudos nessa vertente teórica trouxe o contato com a produção científica disponível. Dentre as quais, mais recentemente, o trabalho desenvolvido pelo Núcleo de Tradução, Estudos e Interpretação das obras dos representantes da Teoria Histórico-Cultural liderado pelas pesquisadoras professora Dra. Zóia Ribeiro Prestes e professora Dra. Elizabeth Tunes, sendo a primeira vinculada à Universidade Federal Fluminense e a segunda à Universidade Federal de Brasília.

Das traduções realizadas pelo núcleo destacamos o livro Sete aulas de L. S. Vigotski sobre os fundamentos da pedologia de Prestes e Tunes, publicado pela editora E-Papers no ano de 2018 e o texto disponível no formato de capítulo cujo título é Uma aula de L. S. Vigotski de Prestes e Estevam, que compõe a coletânea Pedagogia Histórico-Crítica, Educação e Revolução organizada por Orso, Malanchen e Castanha e publicado pela editora Armazém do Ipê no ano de 2017. Essas traduções são originárias do livro Lektsii po Pedologuii (Aulas de Pedologia), resultado de um conjunto de aulas proferidas por Vigotski, organizado e publicado pela editora russa Izdatelskii Dom, da Universidade de Udmursk, no ano de 2001, sendo constituído de duas partes (Prestes; Estevam, 2017).

Com a tradução e a organização de Prestes e Tunes (2018), a primeira parte denomina-se Sete Aulas de L. S. Vigotski sobre os Fundamentos da Pedologia. A segunda parte, traduzida Prestes e Estevam (2017) como O Problema da Idade, foi constituída de oito aulas, sendo algumas 
já publicadas e outras inéditas. Dentre as aulas inéditas será destacado nesse trabalho o capítulo Uma Aula de L. S. Vigotski resultado da tradução para a língua portuguesa, realizada por Prestes e Estevam (2017), do texto/aula inédito O Pensamento do Escolar, proferido por Vigotski em três de maio de 1934, sendo transcrito por estenógrafos no idioma russo.

Tal opção deu-se pela exposição e discussão de aspectos da natureza social e histórica da consciência humana para a constituição de significados e sentidos da realidade contido no texto/aula O pensamento do escolar, como apresentado no trecho a seguir proferido por Vigotski em 1934 e traduzido para a língua portuguesa por Prestes e Estevam (2017):

\begin{abstract}
Eis o que me parece: a consciência é sempre o reflexo da realidade. Esse é o postulado fora do qual é impossível, em geral, analisar a consciência em qualquer ciência. No entanto - assim me parece - ninguém, além das pessoas que simplificam extremamente todos os problemas, disse que a consciência sempre reflete a realidade da mesma forma. Ela sempre reflete a realidade, mas não de forma semelhante. Se a consciência refletisse a realidade da mesma forma, seria impossível falar de desenvolvimento da consciência. A consciência reflete a realidade não especularmente, mas de múltiplas formas. Em cada etapa do desenvolvimento, seja no campo da filogênese, seja no campo da ontogênese, a consciência reflete a realidade de maneiras diferentes (Prestes; Estevam, 2017, p. 211).
\end{abstract}

Ao apreender o texto/aula, questionamentos foram suscitados na tentativa de interpretar como Vigotski abordou os conceitos de obschenie e consciência. A obschenie poderia ser interpretada como interação entre sujeitos? A consciência seria a compreensão da realidade nessa ótica do sujeito? A consciência seria a compreensão individual da realidade pelo sujeito provinda da interação desse com o meio social e pela história, entre as diferentes realidades e formas de mediação?

Nesse sentido, objetivou-se refletir sobre o conceito de consciência e obschenie no texto/aula $O$ pensamento do escolar proferido por Vigotski em 1934 e traduzido para a língua portuguesa por Prestes e Estevam (2017).

\title{
Método
}

Com o objetivo de interpretar o texto/aula $O$ pensamento do escolar fez-se a opção pela análise documental, devido à necessidade de responder aos questionamentos suscitados pela leitura do texto/aula, na busca pela compreensão da Teoria Histórico-Cultural. De acordo com Lüdke e André (1986, p. 38), “[...] a análise documental busca identificar informações factuais nos documentos a partir de questões ou hipóteses de interesse". Contudo, para que a pesquisa possa ser realizada é necessário a obtenção do documento fonte. Lüdke e André explicitam qual 
tipo de texto é considerado como um documento fonte, sendo esses: “[...] os materiais escritos como leis, regulamentos, normas, pareceres, cartas, memorandos, diários pessoais, autobiografias, jornais, revistas, discursos, roteiros, estatísticas e arquivos escolares" (Lüdke; André, 1986, p. 38).

O texto/aula O Pensamento do Escolar é o resultando de uma conferência proferida por Vigotski em três de maio de 1934 na Escola Técnica de Pedagogia Nekrassov, que foi transcrito por estenógrafos e divulgado à comunidade científica no formato de um texto em russo pela editora Izdatelskii Dom, no ano de 2001. Este foi posteriormente traduzido no Brasil para o idioma português por Prestes e Estevam e publicado no formato de capítulo com o título Uma Aula de L. S. Vigotski, na coletânea Pedagogia Histórico-Crítica, Educação e Revolução organizada por Orso, Malanchen e Castanha, pela editora Armazém do Ipê no ano de 2017.

Ao ofertar informações contextualizadas do pensamento de Vigotski sobre a Teoria Histórico-Cultural e alguns dos conceitos que a fundamentam em um discurso, no cenário de uma conferência proferida a professores pouco tempo antes de sua morte e pelo o seu ineditismo no Brasil, o texto/aula despertou interesse para a análise. A origem do texto/aula também foi considerada para a análise, por tratar-se de um texto oriundo de uma conferência, sendo esse um texto oral, no qual Vigotski aproxima à complexidade dos conceitos da Teoria HistóricoCultural a cena de professores em formação. Essa ação, segundo Mello (2010, p. 728), "[...] apresenta os conceitos na complexidade de suas interrelações, de forma acessível aos leitores que iniciam na compreensão do enfoque histórico-cultural [...]".

O procedimento de busca pelo texto/aula ocorreu mediante as atividades de estudo do Grupo de Pesquisa em Inclusão Social - GEPIS, no ano de 2017, na Faculdade de Filosofia e Ciências - UNESP, câmpus Marília/SP. Esse texto foi apresentado pela líder do grupo de pesquisa como inédito e pouco veiculado no meio acadêmico, devido a sua recém-tradução e publicação. Tanto, que poucos eram os pesquisadores que tinham acesso, naquele período, a coletânea que apresentava o texto/aula.

A primeira leitura e discussão do texto/aula se deu no contexto das atividades do grupo de pesquisa. Após, com o aprofundamento da leitura do texto, esse foi recuperado dos arquivos do grupo de pesquisa e reunido com os demais textos que constituem o livro Sete aulas de L. S. Vigotski sobre os fundamentos da pedologia de Prestes e Tunes (2018). Foram realizadas sucessivas leituras com objetivo de elencar os conceitos tratados no texto e, em seguida, a busca por interpretar tais conceitos em associação com as demais obras que constituem a Teoria HistóricoCultural, fundada por Vigotski.

O texto/aula O Pensamento do Escolar foi apreendido por meio da análise da configuração textual, procedimento de análise sistematizado por Mortatti (2000) e utilizado pela autora em investigações e pesquisas na área da História da Educação, literatura brasileira e didática 
em Educação. Mortatti (2000) argumenta que a análise da configuração textual consiste em enfocar os diferentes aspectos que compõem o sentido de um texto. Assim, o procedimento é composto por um conjunto de aspectos característicos, sendo esses:

[...] as opções temático - conteudística (o quê?), estruturais formais (como?), projetadas por um determinado sujeito (quem?), se apresenta como autor de um discurso produzido de determinado ponto de vista e lugar social (de onde?), em um momento histórico (quando?), movido por certas necessidades (por quê?), com propósito (para quê?), visando a determinado efeito (para quem?) e logrado em determinado tipo de circulação, utilização e repercussão (Mortatti, 2000, p. 15).

O procedimento de análise proporciona um trabalho investigativo no que tange à não existência de discursos puros, sendo necessário compreender o sentido da experiência vivida, configurada no diálogo produzido pelo autor, que se remetem às concepções desse e da sua representação da realidade, vivenciados naquele determinado período de tempo (Charaudeau, 2012; Mortatti, 2000). Também, a apropriação desse discurso na contemporaneidade, bem como a razão pela qual o discurso que em cada época foi apresentado, permaneceu (Maingueneau, 2015). Outros aspectos são a sucessão de acontecimentos, o por que essas versões da realidade foram preservadas no tempo e relatadas nesse momento, assim como as diferenças atribuídas, culminando na interpretação do discurso (Mortatti, 2000; Maingueneau, 2015).

O texto/aula trata de uma publicação inédita na obra de Vigotski apresentada na Escola Técnica de Pedagogia Nekrassov, um mês antes de sua morte, para professores de todas as partes da União Soviética. Como também, apresenta a síntese dos conceitos elaborados pelo autor ao longo de sua obra, com destaque para o desenvolvimento da consciência humana e do pensamento.

\section{Análise Do Texto/Aula: o pensamento do escolar}

\section{Contexto Histórico}

A obra de Vigotski contempla, consideravelmente, observações, experimentações e reflexões a respeito da cultura, interação social e dimensão histórica com relação à pedologia. Esses aspectos convergem com a preocupação do autor sobre a compreensão do desenvolvimento humano, por meio do uso de signos e instrumentos, como interativa e historicamente situada. De acordo com Prestes e Tunes (2018, p. 5), “[...] as publicações de Vigotski, mesmo na Rússia, têm sempre uma história que precisa ser contada [...]”. Nesse sentido, faz-se necessário compreender o contexto histórico em que ocorreu a elaboração deste texto/ aula.

Vigotski nasceu em Orsha, na Bielo-Rússia, no ano de 1896. No ano de 1917, ingressou na Universidade de Moscou, nos cursos de Di- 
reito e Filosofia e, posteriormente, lecionou nos cursos de graduação em Psicologia e Pedagogia. Entretanto, foi no ano de 1934 que sintetizou sua obra em um conjunto de aulas proferidas a professores. A formação acadêmica de Vigotski demanda atenção, devido à apropriação das questões legais e legislativas da sociedade, bem como das reflexões a respeito do humano e do desenvolvimento humano. Outro aspecto histórico relevante estava relacionado a presente figura de Stalin, que buscava liquidar a velha guarda Leninista sob o pretexto de que sabiam demais. Dentre esses que despertavam a ira de Stalin, estava Vigotski (Prestes; Tunes, 2018).

O texto/aula em análise foi proferido a professores que estudavam em cursos de qualificação profissional na União Soviética. O fato conduz ao movimento de disseminação do autor a respeito dos conceitos elaborados em sua obra e na exposição, com exemplificações e correlações com a prática escolar, certamente, na tentativa de instruir e formar docentes mais conscientes de sua prática pedagógica. Nesse período de vida, Prestes e Tunes (2018) relatam que Vigotski estava doente e sem condições de redigir seus próprios textos, necessitando de profissionais para realizar a tarefa. Embora a sua condição de saúde estivesse prejudicada, sua produção intelectual continuava ávida, em plena elaboração e preocupação com sua compreensão.

Entretanto, destaca-se a precariedade do registro de suas últimas produções, bem como da introdução de possíveis vieses nos procedimentos de transcrição de suas falas e da tradução dessas. Prestes e Tunes (2018) relatam que o autor não teve tempo hábil para revisar alguns de seus últimos textos, devido ao seu estado de saúde. Outra dificuldade enfrentada por Vigotski, acerca de suas produções e no final de sua vida, configurava-se na figura de Stalin, conhecido como um perseguidor dos opositores a seu discurso esquemático de ideias. Stalin apresentava certo apoio ao desenvolvimento social, mas na realidade, utilizava dessa conduta para diagnosticar e conhecer quais intelectuais pautavam suas produções nessa vertente do pensamento. Esses eram acuados pelo líder e tinham todas as suas produções teóricas destruídas, sendo considerados uma ameaça para a União Soviética (Prestes; Tunes, 2018; Prestes; Estevam, 2017).

Duarte (2000) relata a aproximação de Vigotski aos textos e ao método de Marx na busca de compreender a psique e promover a construção de uma psicologia marxista, que nas palavras de Duarte (2000, p. 80): “[...] era vista por Vigotski não como o surgimento de mais uma entre as correntes da psicologia, mas sim como o processo de construção de uma psicologia verdadeiramente científica”. Por essa busca, Vigotski passa a ter seus conceitos deturpados e a ser perseguido. Contudo, ele falece em consequência da tuberculose antes que pudesse ser surpreendido por Stalin. O líder da União Soviética considerava o autor uma ameaça, por identificá-lo e difamá-lo como idealista, burguês e antimarxista. A obra do autor foi censurada após sua morte e somente após vinte anos desse período, pôde ser acessada (Prestes; Tunes, 2018). 
Embora a tentativa de Stalin fosse de distorcer a representação social de Vigotski, bem como a sua discursividade, a obra do autor apresenta-se com profunda dimensão social e histórica oriundas do socialismo. Duarte (2000, p. 82) destaca que Vigotski pretendia a construção de uma nova sociedade, nas palavras do autor:

\begin{abstract}
Vigotski pretendia fundamentar em Marx a construção da psicologia, pretendia construir uma psicologia marxista e para isso se fazia imprescindível à adoção do método de Marx em sua globalidade. Não há margem para ecletismos nem para justaposições que desconsiderem o núcleo da concepção marxista de ser humano, de sociedade e de história (Duarte, 2000, p. 82).
\end{abstract}

Duarte (2013), assim como Vigotski, enfatiza a importância de um regime político pautado na vertente da verdade, das escolhas conscientes providas do desenvolvimento social, da educação e das relações humanas. Algo defendido por aqueles que lutam, na atualidade, pela humanização.

Os objetos de pesquisa de Vigotski foram intensivamente acompanhados por Lúria ${ }^{1}$ (2015). Ele foi um dos importantes parceiros de pesquisa e interlocutores de Vigotski no Instituto de Psicologia de Moscou. Eles conviveram de 1924 até os últimos dias de vida de Vigotski. De acordo com Lúria (2015, p. 43), “[...] [Vigotski] escolheu como tema a relação entre os reflexos condicionados e o comportamento consciente do homem". Nesse contexto de pesquisa, Lúria (2015) discute que, na antiga União Soviética, havia discussões acirradas na área da psicologia em torno do conceito de consciência e sua natureza subjetiva.

As pesquisas que abordavam essa área estavam sofrendo críticas por parte da comunidade científica da época. Três nomes foram centrais em relação às discussões estabelecidas, sendo esses: Kornilov, um dos críticos à subjetividade da consciência, Bekhterev e Pavlov (Lúria, 2015) estudiosos desse objeto. Vigotski, apesar de todas as críticas, defendeu o estudo da consciência, porém afirmou que ela deveria ser apreendida por métodos objetivos. No entanto, tanto para Lúria (2015) quanto para Vigotski, a conclusão de que a psicologia subjetiva, bem como as tentativas de apreender e observar a consciência a partir de esquemas objetivos, necessitava de uma nova síntese.

Duarte (2013) enfatiza a crítica que Vigotski fez aos pesquisadores que diziam estar construindo uma psicologia marxista, utilizando de dados psicológicos empíricos sem questionar a análise dos dados e os métodos de obtenção. Também, a crítica à adoção da teoria de Marx apenas para aquilo que Duarte denomina de útỉl para a pesquisa no campo da psicologia e, na contemporaneidade, para a educação.

Em Lúria (2015, p. 45), o início do século XX encontrava-se paradoxal, devido às crescentes iniciativas da "[...] redução de eventos psicológicos complexos a mecanismos elementares, que pudessem ser estudados em laboratório através de técnicas experimentais exatas" (Lúria, 2015, p. 45). Para Lúria (2015), Vigotski reconhecia o sucesso dessa iniciativa, mas a criticava por excluir os processos psicológicos superiores.

Educação \& Realidade, Porto Alegre, v. 45, n. 3, e97992, 2020. 
Nesse sentido, Lúria (2015) descreve em seus estudos os autores que leu juntamente com Vigotski na época. Ele menciona Pavlov, Wagner, o qual estudava o comportamento animal, bem como Kurt Lewin, Heinz Werner, William Stern, Karl e Charlotte Buhler e Wolfgang Kohler e Jean Piaget. Lúria (2015) também relatou que Vigotski era o principal teórico marxista do grupo de pesquisa deles. Tanto que, em 1925, durante uma aula que abordava sua vinda para Moscou, Vigotski apresenta uma citação de Marx, a qual se configurou como um de seus conceitos-chaves em seu corpus teórico, sendo:

\begin{abstract}
A aranha realiza operações que lembram as de um tecelão, e as caixas que as abelhas constroem no céu podem tornar sem graça o trabalho de muitos arquitetos. Mas mesmo o pior arquiteto se diferencia da abelha mais hábil desde o princípio, em que, antes de construir com suas tábuas uma caixa, ele já a construiu na sua mente. No final do processo de trabalho ele obtém algo que já existia na sua mente antes que ele começasse a construir. $O$ arquiteto não só modifica as formas naturais, dentro das limitações impostas por essa natureza, mas realiza um propósito próprio, que define os meios e o carácter da atividade à qual ele deve subordinar à sua vontade (Marx, 1867 apud Lúria, 2015, p. 48).
\end{abstract}

Evidentemente, Lúria (2015) sabia que esse tipo de afirmação não era determinante para definir aspectos da obra de Vigotski, mas para ele Marx influenciou Vigotski com relação à origem das formas superiores do comportamento consciente, nas relações do sujeito com o meio social. De acordo com Lúria (2015), Vigotski acreditava que as funções psicológicas superiores surgiam da interação dos fatores biológicos - filogenéticos - o que faz do homem homo sapiens - com fatores culturais, os quais evoluíam ao longo da história.

Para Lúria (2013), a consciência humana é um produto da história, se constitui historicamente e avança no tempo. O autor enfatiza que os processos mentais estão subjugados à vida social, à interação. Por isso, a escola torna-se um locus importante para desenvolver e corrigir comportamentos, adquirir sistemas de linguagem, desenvolver novas motivações, criar novas atividades conscientes e propor novos problemas para a sociedade. A escola poderia ser esse espaço e propor tudo isso se fosse de interesse da sociedade, configurando seus governantes, a compressão histórica da realidade e a liberdade a partir do desenvolvimento da consciência.

No contexto histórico, temos também a aproximação de Vigotski ao psicanalista e filósofo Alfred Adler ${ }^{2}$, com a intenção de compreender as condições educacionais para a formação da criança com deficiência. Dainez e Smolka (2014) analisam o diálogo de Vigotski com Adler sobre o desenvolvimento humano, a educação e a deficiência, pautado no conceito da compensação. Adler associou à formação da personalidade humana a compreensão da compensação, como uma luta subjetiva motivada pelo sentimento de inferioridade, que no contato com Vigotski passa a ser entendida no sentido de luta social. 
Para Vigotski, o conceito de compensação está relacionado com a produção de uma luta social e como o meio social se organiza para receber a criança com deficiência. Assim, Vigotski questiona e supera o conceito de compensação sob uma ótica subjetiva, fundamentando a importância da compensação na concepção materialista, necessitando compreender o desenvolvimento da criança normal e da deficiente correlacionado com as regularidades sociais e biológicas do desenvolvimento humano (Dainez; Smolka, 2014).

Nas palavras de Dainez e Smolka (2014, p. 1103):

\begin{abstract}
O autor [Vigotski] afirma que o plano primário, que diz respeito ao biológico/funções elementares, é reiteradamente transformado pelas novas formações qualitativas que se originam na relação da pessoa com o meio social, dando origem a um novo plano - o das funções psicológicas superiores [...] (Dainez; Smolka, 2014, p. 1103).
\end{abstract}

Alguns dos conceitos elaborados e apresentados na obra de Vigotski são citados e explicados no texto/aula proferido, sendo destacadas as funções psicológicas superiores como a sensação, percepção e memória na constituição do pensamento e, com maior destaque, os conceitos como consciência, generalização e obschenie, os quais serão discutidos ao longo desse texto. Também, a abordagem do desenvolvimento biológico e social do sujeito como aspectos não coincidentes, mas subordinados à historicidade, cultura e às relações sociais na constituição do processo de humanização.

Por meio das relações sociais, é possível ocorrer à dialética primária da sensação com o pensamento. $\mathrm{O}$ resultado deste movimento é o pensamento como atividade consciente e reflexa da realidade e assim, a consciência como produto do desenvolvimento individual e histórico na sociedade. São esses conceitos que conduzem a generalização e a obschenie (Prestes; Tunes, 2018).

\title{
0 Contexto da Tradução
}

A respeito do contexto em que ocorreu a tradução do texto/aula analisado, considera-se a origem russa de um dos tradutores, bem como o objetivo primário de abranger as obras de Vigotski em uma tradução que considere a discursividade da autoria, com respeito à estrutura do texto e à ética, pois como enfatizando por Prestes (2012, p. 11): “[...] a atividade de tradução, compreendo-a como um processo de criação em que o tradutor é um servidor da verdade do autor e suporte para a sua alteridade".

Mesmo os autores apresentando a preocupação com fidedignidade das informações que constituem o texto/aula e o aspecto de um dos autores ter a nacionalidade russa e o domínio do idioma desse país, foi possível detectar o viés de suas representações, bem como a tradução conteudística. Contudo, a necessidade de divulgação da análise dos conceitos apresentados por Vigotski, por meio de uma tradução com- 
prometida com o sentido do texto e de sua autoria, pautada nos múltiplos sentidos da língua russa, bem como na teoria abordada proporcionaram o acesso a esse material e o entendimento de sua constituição.

De acordo com Duarte (1996), a recepção do pensamento de Vigotski configura-se em uma problemática importante, pois a questão da tradução interfere diretamente na compreensão da teoria constituída pelo autor. Além disso, no Brasil, o pensamento de Vigotski é conhecido entre os educadores, sendo lido e estudado por uma ampla quantidade de profissionais da Educação. Duarte (1996) critica publicações que deturpam o pensamento de Vigotski, apresentando-as como divulgadoras de sua escola. Contudo, ao analisar tais publicações é possível perceber a fragilidade das argumentações e do referencial teórico, pois não são abordas as principais obras de Vigotski, consideradas documentos fundamentais para a constituição da Teoria Histórico-Cultural.

Quando Prestes e Estevam (2017) justificam a realização do trabalho de tradução do texto/aula, é pelo ineditismo que enfatizam a necessidade da tradução. A possibilidade da primeira tradução do texto/ aula ser originária da ação de síntese realizada por Vigotski, para além da publicação russa realizada em 2001, possibilitou o acesso e fomentou maior apropriação de seus conceitos por todos os professores e pesquisadores, além de promover novas pesquisas no campo do desenvolvimento humano e do pensamento conceitual.

\section{Síntese dos Conceitos Apresentados na Última Aula}

O texto/aula foi uma síntese dos conceitos da Teoria HistóricoCultural em relação à reflexão sobre o pensamento conceitual considerado por Vigotski e ainda pouco explorado, principalmente, quanto aos conceitos da consciência, generalização e obschenie.

A questão da generalização foi exposta sobre a ênfase, de que “[...] o humano se humaniza na relação com o outro e nessa relação aprende a dominar os instrumentos culturais criados historicamente pela sociedade humana" (Prestes; Estevam, 2017, p. 208). Para Vigotski dominar é ter consciência, pois esta é reflexo da realidade, mas de maneira diferenciada no tempo e, por isso, é desenvolvida (Prestes; Estevam, 2017).

$\mathrm{O}$ autor explicita a tomada de consciência das próprias funções psicológicas superiores, afirmando que essa é um ato voluntário, pois o desenvolvimento não se inicia com o pensamento. O desenvolvimento relativamente complexo da percepção da memória, da atenção e de outras funções mais simples e elementares é pré-requisito para originar o pensamento. Assim, a consciência reflete a realidade de múltiplas formas e ocorre o salto dialético na passagem da sensação ao pensamento.

A percepção é um processo complexo que envolve probabilidade, análise e síntese dos aspectos capturados pela sensorialidade, a qual conta com o apoio da atenção e da memória. Além disso, ela depende de práticas humanas históricas, categorias de objetos, designação de fenômenos e atividades ligadas à vida prática (Lúria, 2013). A percepção 
torna-se vinculada à constituição da consciência, uma vez que é a responsável pela atribuição de sentido e significado às impressões oriundas da rota sensorial (Martins, 2013).

A memória não constitui uma simples maturação, mas uma transformação/metamorfose cultural, a qual as estratégias e técnicas, mediadas pelos signos, contribuem para a fixação da experiência na memória, que se desenvolveram no decorrer do desenvolvimento cultural (Vigotski, 2001; Vigotski; Lúria, 1996). A memória evoca imagens daquilo que se aprendeu no passado, filo e ontogeneticamente (Martins, 2013).

A atenção contribui para a organização do comportamento, de acordo com Vigotski e Lúria (1996, p. 197), “[...] a atenção torna-se uma função real somente quando a própria criança domina os recursos de criar os estímulos adicionais que centram sua atenção, em cada um dos componentes de uma situação e que eliminem tudo mais que se encontra em segundo plano”. A atenção se organiza em duas premissas: sua natureza social e seu desenvolvimento, no que diz respeito à estrutura da atividade (Martins, 2013).

Sobre a linguagem e o pensamento, Vigotski (2001) e Vigotski e Lúria (1996) teorizaram que ambos são indissociáveis. Inicialmente, a linguagem exprime o conteúdo do pensamento. Com o passar do desenvolvimento, na adultez e com a internalização cultural, o sujeito torna-se capaz de formular, no âmbito do pensamento, suas ações em uma atividade e, posteriormente, verbalizá-la (Vigotski; Lúria, 1996). A linguagem é um sistema de signos que contribui com a interação entre os homens, e o pensamento consiste no estabelecimento de conexões mentais e dados oriundos da realidade, os quais foram aprendidos pela sensorialidade e percepção e designados pelos signos imbricados pela linguagem (Martins, 2013).

Vigotski tenta em todo o texto/aula esclarecer que a consciência no ser humano decorre da natureza social e histórica pois, nas palavras do autor, “[...] essa não é fruto do desenvolvimento humano, mas um produto do desenvolvimento histórico da sociedade humana, que surge, cresce e altera-se na generalização das pessoas" (Prestes; Estevam, 2017, p. 212)

Nas palavras de Lúria (2013, p. 25),

[a] consciência humana deixa, portanto, de ser uma 'qualidade intrínseca do espírito humano', sem história e inacessível à análise causal. Começamos a entendê-la como a forma mais elevada de reflexo da realidade criada pelo desenvolvimento sócio-histórico: um sistema de agentes que existe objetivamente produz a consciência humana, e análise histórica a torna acessível. [...]. Ao aprender atividades complexas com objetos, corrigindo seu próprio comportamento através de relações sociais e adquirindo sistemas linguísticos complexos, as crianças são levadas, invariavelmente, a desenvolver novas motivações, criar novas formas de atividade consciente e propor novos problemas (Lúria, 2013, p. 25). 
Também, foi cuidadosamente exposto por Vigotski que a consciência e a generalização são frutos do trabalho desde o desenvolvimento infantil e no ambiente escolar. Vigotski exemplifica várias situações da rotina escolar em que os conceitos apresentados podem ser utilizados e, assim, proporcionar à criança um processo educativo coeso e com múltiplos sentidos, sendo estes favorecedores da aquisição do conhecimento e das funções psicológicas superiores (Smolka, 2009).

O estudo dos conceitos citados levou a alguns questionamentos com relação ao contexto histórico e o momento de concepção do texto/ aula aos aspectos que constituem a discursividade do autor, sendo assim sugiram: Por que Vigotski fala em pedologia? Por que explicita as especificidades desse estudo diferenciando-o das outras ciências? Por que o desenvolvimento infantil?

A palavra pedologia, na tradução de Prestes e Tunes (2018), significa ciência da criança, conceito que para os autores não foi suficientemente expresso, de modo que tornasse esse objeto claro a respeito do que de fato se estuda na pedologia. Uma hipótese seria o acontecimento da morte de Vigotski, não lhe dando tempo suficiente para discutir essa questão como o autor gostaria de ter teorizado.

Entretanto, o que Prestes e Tunes (2018) enfatizam a respeito da pedologia consiste no fato dessa ciência ater-se ao desenvolvimento da criança, mas que de certa forma, a Pedagogia e a Psicologia realizam esse estudo. De acordo com as autoras, a chave para essa questão está na palavra desenvolvimento. Nas palavras das autoras:

$$
\begin{aligned}
& \text { Como qualquer outro processo, ele é histórico, ou seja, } \\
& \text { transcorre no tempo; tem início, tem etapas temporais } \\
& \text { determinadas do seu desenvolvimento e tem fim. Contu- } \\
& \text { do, não está organizado no tempo que - se é possível dizer } \\
& \text { assim - o seu ritmo coincida com o ritmo do tempo; não } \\
& \text { está organizado de forma que, em cada intervalo de tem- } \\
& \text { po cronológico, a criança percorra um determinado tre- } \\
& \text { cho em seu desenvolvimento (Prestes; Tunes, 2018, p. 18). }
\end{aligned}
$$

Esse pode ser um dos obstáculos a serem transpostos pela educação, inclusive brasileira. O fato de a criança em idade escolar completar um ano em determinada série não significa que ela tenha se desenvolvido. Ao refletir as teorizações de Vigotski, a partir da tradução, foi discutido que o ritmo do desenvolvimento "[...] não coincide com a contagem cronológica do tempo [...]” (Prestes; Tunes, 2018, p. 18). Nesse sentido, não seria ousado dizer que esse pensamento poderia ser generalizado para todas as extensões da vida escolar? Portanto, os meses e anos de desenvolvimento estarão subordinados ao tempo e lugar onde a criança se localiza histórica e culturalmente.

Por isso, em sua última aula, Vigotski fala em conteúdo da criança pensando o tempo e lugar histórico e, de acordo com sua fala, seria nesse âmbito o espaço onde surgiriam as neotransformações, ou seja, o processo de desenvolvimento. Surgiria assim, uma “[...] idade pedológica, ou seja, o nível de desenvolvimento que a criança realmente atingiu, 
além de sua idade segundo a certidão de nascimento [...]" (Prestes; Tunes, 2018, p. 20).

Portanto, esse talvez seja um dos entraves presenciados na escola brasileira, na qual os estudantes não se desenvolvem seguindo os princípios teóricos, como os apresentados por Vigotski, mas pela idade cronológica que consta na certidão de nascimento deles. Assim, cria-se um impasse na compreensão do desenvolvimento da criança em meio às ações pedagógicas coletivas. Nesse cenário, cabe a reflexão: Como compreender o desenvolvimento da criança, nessa perspectiva teórica, se a base da atualidade está pautada em outros princípios?

Em sua aula Vigotski explicita a importância das neotransformações, as quais resultam de dissoluções ocorridas entre a criança, sua personalidade, a realidade e o meio. Para o autor esses elementos compõem a estrutura da consciência (Prestes; Estevam, 2017; Tanamachi, 2010). Além disso, explicita sua preocupação com o escolar, ou seja, a criança que se encontra nessa etapa.

Tais aspectos podem permitir a inferência de que a criança é motivo e foco educacional nos estudos de Vigotski, pois ela está iniciando sua vida histórica e social (Mello, 2010). Ela estará no início de um longo processo de desenvolvimento, com vistas a internalizar e se apropriar de elementos, ferramentas e signos criados pelo homem ao longo da história (Tanamachi, 2010; Mello, 2010). Além disso, estará subordinada aos elementos próprios de sua cultura. Diante do exposto, cabe resgatar as teorizações de Prestes e Estevam (2017) os quais afirmam, a partir de reflexões sobre os conceitos de Vigotski

$$
\begin{aligned}
& \text { [...] que o humano se humaniza na relação com o outro } \\
& \text { e nessa relação conhece e aprende a dominar os instru- } \\
& \text { mentos culturais criados historicamente pela sociedade } \\
& \text { humana. E dominar é ter consciência. E a consciência, } \\
& \text { para Vigotski, é refletir a realidade (Prestes; Estevam, } \\
& \text { 2017, p. 208). }
\end{aligned}
$$

Para alcançar esse desenvolvimento, a criança precisa acessar os conceitos e passar da apreensão empírica dos objetos da cultura para as abstratas, de modo mediado (Tanamachi, 2010). Por essa razão, as funções psicológicas superiores serão determinantes (Martins, 2013) porque, por meio delas, os seres humanos se tornam capazes de analisar, generalizar e codificar suas experiências, além de interagir com o meio ambiente (Lúria, 2013). A sensorialidade com o apoio da atenção contribuirá para que a criança acesse o objeto. No âmbito da percepção, a criança com o auxílio da memória irá buscar um significado e, por meio da linguagem e do pensamento - estes elementos fundantes - irá apreender o objeto de modo abstrato (Prestes; Estevam, 2017). Portanto, “[...] o conceito ainda pode conter momentos concretos e abstratos, contudo, nem todo conceito será abstrato com total distanciamento da realidade, mas sim de retorno a ela [...]" (Prestes; Estevam, 2017, p. 214).

Martins (2013) também apresenta uma síntese a esse respeito. De acordo com a autora:

Educação \& Realidade, Porto Alegre, v. 45, n. 3, e97992, 2020. 
[...] a superação do pensamento empírico, subjugado à captação sensorial imediata do objeto, em direção ao pensamento por conceitos, cuja lógica interna demanda uma relação indireta, isto é, abstrata e mediada, com o objeto captado sensorialmente. Da mesma forma, apenas essa dissolução tornará possível o autocontrole da conduta (Martins, 2013, p. 128).

A percepção é um processo complexo que envolve probabilidade, análise e síntese dos aspectos capturados pela sensorialidade, a qual conta com o apoio da atenção e da memória. Além disso, ela depende de práticas humanas históricas, categorias de objetos, designação de fenômenos e atividades ligadas à vida prática (Lúria, 2013).

No texto/aula O Pensamento do Escolar, Vigotski aponta dois conceitos que considera fundamentais para a estrutura da consciência, a generalização e obschenie. Para ele "[...] todo significado da palavra infantil é uma generalização e uma única generalização, ou seja, o conceito está para o outro conceito sempre numa determinada relação comum (conjunto) [...]” (Prestes; Estevam, 2017, p. 216).

Assim, surge a necessidade de que os signos se tornem generalizáveis e, no contato com o outro, alcancem patamares universais em termos de compreensão e uso. A relação de união comum ou conjunto permitirá a criança que relações sejam estabelecidas como, por exemplo, flor em relação a rosa, insetos em relação a formiga, entre outras exemplificações dadas pelo autor. Um conceito generalizável permite que outros raciocínios sejam gerados. Quantos raciocínios não podem ser criados a partir do numeral cinco, conforme expôs Vigotski? Ao indagar os professores a esse respeito, o autor explica que cada criança, em etapa distinta de desenvolvimento, apresentará meios próprios de generalização, os quais permitirão que a realidade seja refletida na consciência (Prestes; Estevam, 2017).

Outros dois pontos cruciais a serem destacados e relacionados diretamente com o desenvolvimento infantil são, de acordo com Vigotski, as relações de união comum como momentos imprescindíveis e determinantes para a criança, pois o outro consiste na generalização. Nesse cenário, imagine um conceito científico generalizável? Ele representará a síntese histórica e ainda poderá ser compreendido como parte de um determinado sistema de conceitos. Com isso, as relações de união comum do pensamento, da obschenie da generalização, bases da consciência, em conjunto com as funções psicológicas superiores desenvolvidas, proporcionam ao escolar a condição de atingir sua emancipação (Mello, 2010).

Os aspectos abordados anteriormente conduzem a questionamentos quanto a sua efetivação no ambiente escolar. Assim, pode-se pensar sobre por que Vigotski proferiu sua última aula para professores em um curso de formação? Porque, para o autor, a idade escolar “[...] é a passagem, principalmente do meio visual-sensitivo de refletir a realidade para a generalização" (Prestes; Estevam, 2017, p. 224). 
Nesse sentido, o autor talvez quisesse destacar aos professores que antes de ir à escola a criança apresenta uma forma de generalização, mas a partir da aquisição do meio visual-sensitivo passa a refletir a realidade, esse escolar inicia a compreensão do que está aparente na realidade, mas não seus aspectos profundos e generalizáveis. Para Vigotski ao adentrar o universo escolar, a criança passa a aproximar-se da possibilidade de aquisição da estrutura da consciência, sendo possível concluir que no ambiente escolar são desenvolvidas a consciência e as funções psicológicas superiores (Mello, 2010). Os conceitos regentes para o alcance desses objetivos são a generalização e obschenie, juntamente com o sistema de relação de união comum (conjunto).

Por meio de tais aspectos, é possível refletir o quanto se faz necessário que os professores possuam o conhecimento desses conceitos, como fizeram os professores que estavam com Vigotski. O autor demonstrou tais aspectos aos professores, quando expôs o trecho a seguir, que sem a instrução mediada:

[...] a criança não vai conseguir se emancipar, não vai conseguir se desprender da base visual-sensitiva do pensamento, da percepção e da memória, então, conserva-se a lei de que a criança pensa com mais facilidade quando vê, ou quando se apoia na experiência, do que quando a ideia está entregue a si mesma (Prestes; Estevam, 2017, p. 222).

De acordo com Mello (2010) a importância do meio e da figura do professor são fundantes nesses passos de desenvolvimento da criança, pois quando estão no ambiente escolar e são considerados os processos de generalização há a aquisição de conhecimento científico, pois a criança se eleva para o estágio de obschenie, porque "[...] qualquer movimento, qualquer exposição de saberes são formas de obschenie com a criança" (Prestes; Estevam, 2017, p. 223). Portanto, se a obschenie for rompida, de acordo com Vigotski, como o professor poderá transmitir saberes profundos e importantes? Nesse contexto, a criança não terá estrutura para comportá-los. Vigotski exemplifica tais aspectos no trecho a seguir:

Por que a criança estudava e não entendia o verdadeiro sentido da palavra? Aqui tínhamos um típico caso de rompimento da obschenie que se expressava no fato de que o professor transmitia uma ideia profunda - e a cabeça do aluno tornava-se rasa; o professor transmitia uma ideia rica - que na cabeça do aluno tornava-se pobre. A profundidade e a esfera, a adequabilidade dessa obschenie se rompiam. Eis a raiz principal, acessível ao nosso estudo contemporâneo, que de forma mais próxima define o curso da instrução e se depara com essa questão de cultivar na idade escolar um sistema de obschenie e generalização (Prestes; Estevam, 2017, p. 223).

Ao dialogar com os professores, Vigotski apresentou um importante papel a ser considerado e executado no ambiente escolar. Sem alcançar a obschenie e generalização a criança não terá como acessar o 
conhecimento, tornando-se difícil o desenvolvimento da consciência e das funções psicológicas superiores. Ela passará pelo período de escolarização sem atingir seu desenvolvimento completo, pois enquanto a escola focar a idade cronológica da criança e o professor não promover a obschenie e a generalização no momento que dissemina os saberes, se tornará complicado para a criança maximizar seu desenvolvimento. Ela estará impedida de acessar aqueles saberes, como também não terá estrutura para acessá-los e para adquirir sua emancipação.

\section{Considerações Finais}

Ao enfatizar o estudo do desenvolvimento da criança, Vigotski teorizou e constatou importantes aspectos para a pedagogia e a psicologia, por meio da aquisição das funções psicológicas superiores. Ao abordar conceitos como percepção, atenção, memória e linguagem na constituição do pensamento, para o desenvolvimento da consciência social e histórica, o autor apresentou o processo de humanização como protagonista de todo o desenvolvimento histórico e social do humano, que culmina na generalização e obschenie.

Nesse sentido, podemos refletir o conceito de obschenie como a interação entre sujeitos, pautada no conceito de linguagem. Contudo, a humanização só poderá ser conquistada quando for permitido à criança o desenvolvimento da consciência, por meio da compreensão de sua realidade apoiada no quanto essa consegue generalizar os aspectos sociais, culturais e históricos vivenciados. O cenário desse processo deve ocorrer na educação infantil e desdobrar-se por toda a escolarização da criança, sendo o professor o mediador de todo o desenvolvimento humano e fomentador da emancipação dessa pessoa.

A síntese desses conceitos foi exposta pelo próprio Vigotski no texto/aula $O$ pensamento do escolar que, traduzido para o português no capítulo Uma Aula de L. S. Vigotski por Prestes e Estevam, demonstrou o complexo pensamento de Vigotski a respeito da convergência entre a cultura, a interação social e a dimensão histórica. Como também, por meio da busca por compreender a importância do processo de humanização pela relação do homem com seu semelhante, pelos caminhos para a construção de signos e sentidos na aquisição da consciência e generalização, vislumbrando a promoção da autonomia do pensamento.

A possibilidade de assimilar o caminho e a ênfase à pedologia, que proporcionaram a Vigotski múltiplos sentidos em sua obra e características para além da contemporaneidade, caracteriza sua teoria, ao mesmo tempo, como pioneira para sua época e, na atualidade, como uma contribuição inestimável para a Educação. Vigotski pauta-se em um cenário socialista e com forte repressão àqueles que defendiam a emancipação do humano, por meio de ferramentas promotoras de seu desenvolvimento, valendo ao autor a característica da transgressão e do enfrentamento ao controle político da época. Tal fato ainda é valorizado e utilizado como fonte de inspiração atualmente, devido à luta contra o processo de alienação e desvalorização dos processos educa- 
cionais pelo capitalismo, fortalecido nas divisões das classes sociais em um estado democrático de direito.

$\mathrm{O}$ acesso às obras de Vigotski pelo ocidente é fruto do trabalho de traduções de seus livros e textos. Por meio da produção de alguns grupos de pesquisadores, entre esses, alguns brasileiros, como exemplo as pesquisadoras Prestes e Tunes, foi possível conhecer e aprofundar estudos a respeito das produções textuais de Vigotski. Contudo, variáveis devem ser consideradas no processo de tradução e de compreensão do sentido e conotação da teorização de Vigotski e dos objetivos que levam vários pesquisadores a buscarem refletir suas constatações, conceitos e obra.

A importância em considerar o ambiente educacional como o local primário do desenvolvimento humano, mediado pelo conhecimento e por um humano que pode proporcionar a instrução e mediação por meio da interação, foi destacado. A tradução de textos de Vigotski no Brasil proporcionou mais uma importante fonte de acesso ao seu discurso fundante, que necessita ser refletido e aprofundado, no sentido de promover o desenvolvimento das crianças, o avanço da sociedade e a compreensão de que a Educação é ferramenta de transformação para uma nação, independente do universo político ao qual ela pertença ou vivencie, e que o professor é o protagonista da ação da obschenie.

Quando uma criança inicia seu desenvolvimento, para Vigotski esse processo ocorre de modo relativamente complexo e não cronológico, por meio da aquisição da percepção, atenção, memória e linguagem. Assim, origina-se o pensamento, que por meio das sensações e da dialética é obtido. Para o autor a sensação é a forma primária da consciência e o pensamento a forma superior da atividade consciente. Nesse contexto, considera-se a natureza social e histórica da consciência como produto social do desenvolvimento humano, reflexão das múltiplas formas da realidade e de seu domínio. Contudo, esse somente ocorre por meio da generalização promovida pela ação mediada, pela obschenie e pela linguagem nas relações entre o sujeito e o mundo.

Por isso, a preocupação de Vigotski em sintetizar os conceitos elaborados em sua teoria para professores em formação. A tentativa de esclarecer, exemplificar, contextualizar e demonstrar aos futuros professores a necessidade de refletir os conceitos da teoria Histórico-Cultural na prática pedagógica, bem como compreender e explorar o pensamento conceitual no processo de desenvolvimento da criança. Nas palavras do autor: "A consciência humana é produto do desenvolvimento histórico da sociedade humana [...], altera-se na generalização das pessoas" (Prestes; Estevam, 2017, p. 203).

Vigotski realizou suas pesquisas em um momento histórico de reorganização e mudanças profundas das estruturas da sociedade na União Soviética, sendo possível observar a importância da formação sócio-histórica dos processos mentais. Ao relacionarmos tais aspectos ao momento histórico de constituição desse texto, podemos ter a sensação da ausente mudança social e histórica no Brasil. Contudo, nes- 
ses momentos de rupturas surgem lacunas a serem vislumbradas, bem como oportunidades para pensar questões sobre a formação histórica de alunos, professores e da sociedade, almejando a Educação para todos, por meio dos processos mentais. Essa reflexão poderá apresentar a obviedade das questões tratadas no texto/aula, que contribuirá para a constituição da identidade brasileira, da consciência social e histórica do país, talvez da sua emancipação. Entretanto, a humanização e liberdade do homem brasileiro ainda é um ideal, dada às condições históricas e sociais do Brasil ${ }^{3}$.

Recebido em 5 de novembro de 2019 Aprovado em 9 de junho de 2020

\section{Notas}

1 Psicólogo russo (1902-1977). Era especialista na psicologia do desenvolvimento e formou-se pela Universidade Estatal de Kazan.

2 Filósofo e Psicólogo austríaco (1870-1937). Foi fundador da Escola para Psicologia Individual. Suas áreas de maior atuação foram: psicoterapia e pedagogia. 3 Auxílio financeiro Projeto nº798/2018 PROEX/CAPES.

\section{Referências}

ARROYO, Miguel González. Imagens Quebradas: trajetórias e tempos de alunos e mestres. 4 ed. Petrópolis, Rio de Janeiro: Vozes, 2007.

ARROYO, Miguel González. Outros Sujeitos, Outras Pedagogias. 2 ed. Petrópolis, Rio de Janeiro: Vozes, 2014.

CHARAUDEAU, Patrick. Linguagem e Discurso: modos de organização. Coordenação da equipe de tradução Angela M. S. Corrêa \& Ida Lúcia Machado. 2 ed. São Paulo: Contexto, 2012.

DAINEZ, Debora. Desenvolvimento e Deficiência na Perspectiva HistóricoCultural: contribuições para educação especial e inclusiva. Revista de Psicología, n. 26, v. 2, p. 1-10, 2017. Disponível em: <http://dx.doi.org/10.5354/07190581.2017.47948>. Acesso em: 25/06/2019.

DAINEZ, Debora; SMOLKA, Ana Luiza Bustamante. O Conceito de Compensação no Diálogo de Vigotski com Adler: desenvolvimento humano, educação e deficiência. Educação e Pesquisa, São Paulo, v. 40, n. 4, p. 1093-1108, out./dez. 2014. Disponível em: <http://dx.doi.org/10.1590/s1517-97022014071545>. Acesso em: 10/04/2018.

DUARTE, Newton. Educação Escolar, Teoria do Cotidiano e a Escola de Vigotski: polêmicas do nosso tempo. Campinas: Autores Associados, 1996.

DUARTE, Newton. A Anatomia do Homem É a Chave da Anatomia do Macaco: a dialética em Vigotski e em Marx e a questão do saber objetivo na educação escolar. Educação \& Sociedade, ano XXI, n. 71, jul. 2000.

DUARTE, Newton. A Individualidade Para Si: contribuição a uma teoria histórico-crítica da formação do indivíduo. 3. ed. Campinas: Autores Associados, 2013.

FREIRE, Paulo. Educação como Prática da Liberdade. 30 ed. Rio de Janeiro: Paz e Terra, 2007. 
FREIRE, Paulo. Pedagogia da Autonomia: saberes necessários à prática educativa. 57 ed. Rio de Janeiro/São Paulo: Paz e Terra, 2018.

GOFFMAN, Erving. Estigma: notas sobre a manipulação da identidade deteriorada. Rio de Janeiro: Zahar, 1963.

LÜDKE, Menga. ANDRÉ, Marli. Pesquisa em Educação: abordagens qualitativas. São Paulo: EPU, 1986.

LÚRIA, Alexander Ramanovich. Desenvolvimento Cognitivo: seus fundamentos culturais e sociais. Trad. Fernando Lomongeli Gurgueira. 7 ed. São Paulo: Ícone, 2013.

LÚRIA, Alexander Ramanovich. A Construção da Mente. 2 ed. São Paulo: Ícone, 2015.

MAINGUENEAU, Dominique. Discurso e Análise do Discurso. Trad. Sírio Possenti. 1 ed. São Paulo: Parábola Editorial. 2015

MARTINS, Lígia Márcia. O Desenvolvimento do Psiquismo e a Educação Escolar: contribuições à luz da psicologia histórico-cultural e da pedagogia histórico-crítica. Campinas: Autores Associados, 2013.

MELLO, Sueli Amaral. A Questão do Meio na Pedologia e suas Implicações Pedagógicas. Psicologia USP, São Paulo, v. 21, n. 4, p. 727-739, 2010.

MORTATTI, Maria do Rosário Longo. Os Sentidos da Alfabetização. São Paulo: UNESP, 2000.

OMOTE, Sadao. Estigma no Tempo da Inclusão. Revista Brasileira de Educação Especial, Marília, v. 10, n. 3, p. 287-308, 2004.

ORSO, Paulino José; MALACHEN, Julia; CASTANHA, André Paulo. Pedagogia Histórico-Crítica, Educação e Revolução: 100 anos de revolução russa. Campinas: Armazén do Ipê, 2017.

PRESTES, Zoia Ribeiro; ESTEVAM, Lucas Gago. Uma aula de L. S. Vigotski. In: ORSO, Paulino Jose; MALANCHEN, Julia; CASTANHA, André Paulo (Org.). Pedagogia Histórico-Crítica, Educação e Revolução: 100 anos da Revolução Russa. 1 ed. Campinas: Armazém do Ipê, 2017. P. 207-224.

PRESTES, Zóia. Quando Não É Quase a Mesma Coisa: traduções de Lev Semionovitch Vigotski no Brasil. Campinas: Autores Associados, 2012.

PRESTES, Zóia; TUNES, Elizabeth. (Org. e Trad.). Sete Aulas de L. S. Vigotski sobre os Fundamentos da Pedologia. Rio de Janeiro: E- Papers, 2018.

SAVIANI, Dermeval. Educação: do senso comum à consciência filosófica. 19 ed. Campinas: Autores Associados, 2013.

SMOLKA, Ana Luiza Bustamante. Comentários. In: VIGOTSKI, Levi Semyonovich. Imaginação e Criação na Infância: ensaio psicológico: livro para professores. Apresentação e comentários Ana Luiza Smolka; Trad. Zóia Prestes. São Paulo: Ática, 2009. P. 136.

SKLIAR, Carlos. A Inclusão Que É 'Nossa' e a Diferença Que É do 'Outro'. In: RODRIGUES, Davi (Org.). Inclusão e Educação: doze olhares sobre a educação inclusiva. São Paulo: Summus, 2006. P. 15-34.

TANAMACHI, Elenita Ricio. A Mediação da Psicologia Histórico-Cultual na Atividade de Professores e do Psicólogo. In: MENDONÇA, Sueli Guadalupe Lima; MILLER, Stella (Org.). Vigotski e a Escola Atual: fundamentos teóricos e implicações pedagógicas. 2 ed. Araraquara: Junqueira \& Marin; Marília: Cultura Acadêmica, 2010. P. 65-84. 
VIGOSTSKI, Lev Semyonovich; LÚRIA, Alexander Ramanovich. Estudos Sobre a História do Comportamento: o macaco, o primitivo e a criança. Trad. Lólio Lourenço de Oliveira. Porto Alegre: Artes Médicas, 1996.

VIGOTSKI, Lev Semyonovich. Obras Escogidas: problemas de psicologia general. Trad. José Maria Bravo. Madrid: A. Machado Libros, 2001.

Amabriane da Silva Oliveira Shimite é doutoranda e Mestra em Educação pela Universidade Estadual Paulista - UNESP, câmpus Marília/SP. Bolsista CAPES. Atua em trabalhos com a temática: deficiência e Ensino Superior. Possui experiência como docente no Ensino Superior, responsável pelo atendimento educacional especializado e pela elaboração de materiais adaptados para a estudantes com deficiência visual. É membro do grupo de pesquisa Trabalho, Deficiência e Saúde.

ORCID: http://orcid.org/0000-0003-1523-7097

E-mail: dsshimite@gmail.com

Fabiana Oliveira Koga é doutora e Mestra em Educação pela Universidade Estadual Paulista - UNESP, câmpus Marília/SP. Durante o mestrado foi bolsista CNPq e, no doutorado foi bolsista FAPESP. É autora do livro "Precocidade e Superdotação Musical" e autora, com o apoio da FAPESP, do "Protocolo para Screening de Habilidades Musicais”. É membro do Grupo de Pesquisa para o Desenvolvimento do Potencial Humano (GRUPOH).

ORCID: http://orcid.org/0000-0002-4646-1537

E-mail: fabianapsicopedagogiamusical@gmail.com

Editora-responsável: Carla Vasques

Este é um artigo de acesso aberto distribuído sob os termos de uma Licença Creative Commons Atribuição 4.0 Internacional. Disponível em: <http:// creativecommons.org/licenses/by/4.0>. 